\title{
Breath-As Subject, in Form, in Performance: An Interview with Michael Symmons Roberts
}

\author{
Michael Symmons Roberts with David Fuller
}

David Fuller: Michael Symmons Roberts is going to discuss his novel, Breath, and a range of earlier and later poems. One background to this is a discussion Michael and I had at the Edinburgh International Book Festival in 2017, which prompted Michael to think about how his underlying interest in writing about breath had family roots. I'd like to begin by asking Michael about those as an introduction to our discussion.

Michael Symmons Roberts: As has happened to me before, sometimes you are invited to talk about a theme in your work that you hadn't realised was there until you are invited to talk about it. I do seem to be obsessed with breath and breathlessness. Talking in Edinburgh it all started to coalesce with me. My mother's family is from Salford, near Manchester. My maternal grandfather worked in the docks. He was a clerk

M. S. Roberts

The Manchester Writing School, Department of English, Manchester Metropolitan University, Manchester, UK

D. Fuller $(\varangle)$

University of Durham, Durham, UK

(C) The Author(s) 2021

D. Fuller et al. (eds.), The Life of Breath in Literature, Culture

and Medicine, Palgrave Studies in Literature, Science and Medicine, https://doi.org/10.1007/978-3-030-74443-4_24 
for cargo ships, dealing with bills of lading, and he suffered from severe asthma. One of my childhood memories is of my grandfather struggling for breath, regularly being rushed to hospital. I had heard that in his twenties he was a good runner, and ran for the Salford Harriers, one of the great athletics clubs in Manchester. Then asthma came to dominate his life. I remembered as a child seeing family photos in which before a certain point in the 1960s he looked like a cadaver. There's no other way of saying it: he looked absolutely drawn, quite different from how I remember him in late childhood. You never know how much these things are family myth, but it was said that he met on the docks someone who had come off a merchant ship from Germany who heard him struggling for breath and said to my grandfather, 'Are you asthmatic? I am asthmatic, and my doctor in Germany has just put me on cortisone. It has turned my life around'. So my grandfather asked his doctor to put him on cortisone, and he was the first asthmatic in the country to be put on cortisone. I don't know if this is true, but this was the family's story. Cortisone shortened his life, but he lived into his early seventies. He had inhalers that he used all the time, but he was never afterwards rushed into hospital. The illness was stabilised: he lived a normal life. All the family photos after that look different. Part of that is, of course, the effect of the steroids, but also it is just that he comes to life through the record of family photos. So that is a quite dramatic thing when you are growing up, and dominant, I think, in our family. I grew up with the idea that we were a family with lung trouble, breathing troubles, and I was the kind of child who had coughs I could never get rid of. This culminated in double pneumonia. I was off school for months when I was about six. I remember being quite proud of having double pneumonia. It was a serious-sounding thing-double. I remember very little about it apart from having a cough for a long time and getting out of school. Again, I think it reinforced the sense that breath was something not to be taken for granted, something fugitive, something that our family didn't have a good record with. Later, of course, you don't think about these things. You start writing, and you realise this keeps coming up. It was a conversation with David that drew this out. That's the family background.

$D F$ : Obviously breathing is a central issue in your novel, Breath. ${ }^{1}$ I've asked Michael to talk about the relation between the novel's main elements - the aftermath of a civil war; issues of medicine and physical treatment; and a related issue of spiritual healing. One aspect of how the lung disease narrative relates to the civil war is about the sense of different kinds of air accessed by different kinds of lungs. I've also asked Michael to talk about a language issue. Several critics have said Breath 
is the novel of a poet. Sometimes on the page there are two different typefaces. In these different typefaces the novel presents the reader with different kinds of language, a language of passion and a language of bureaucracy, which find trouble meeting. All sorts of real experience, you might say, find difficulty meeting the language of bureaucracy-but I leave Michael to describe this.

MSR: It is worth saying that I don't think of myself as a novelist. I think of myself as a poet who has written two novels. There's a strong tradition of poets who write two novels!

The genesis of the novel came from an opera I was working on, The Sacrifice. I've worked for a long time with the composer James MacMillan. The Sacrifice was written for Welsh National Opera. As with a lot of new commissions in opera, the whole creative team is assembled from the start. You start talking about the work before anything is done, which is odd but also very creative. Poets just tend to get on with it, but this is a different kind of process. So we were put together, Jimmy and I and the director, Katie Mitchell. Katie's method is to immerse everybody in research from the outset- to throw lots of material at us. The story we had in mind was about the aftermath of a civil conflict in a Balkans-like state, and the difficulty of healing after that sort of neighbour on neighbour violence. Meetings were set up; we watched films; we read eye-witness accounts; we were thoroughly steeped in the subject. With the creation of an opera the librettist goes first. So we did the research, I wrote my libretto, and adjusted it, and so on. The composer comes in, and the director comes in, but I still had all this material going round in my head. I found that everything I tried to write after the opera was finished was circling back around the idea of civil conflict. I didn't know how to write about it all. Then I met somebody I worked with briefly when I was a producer at the BBC. He had given up producing at the BBC because his first love was flying: he wanted to be a pilot, and he managed it. He was flying transplant organs around Britain because that was a way of getting your flying hours up. I thought this was bizarre, so I asked more about it. 'What is it like with a heart? What is it like with a lung?' He said, 'You just strap it into the passenger seat. Sometimes you are flying all night'. I thought how strange that must be. The one that interested me most was the lung, and the lung transplant was what unlocked the idea of how to write about the aftermath of a civil conflict. In the novel a lung is transplanted from a young victim in the south to an old man in the north who has a past that he is not talking about which has something to do with the conflict. So the lung gets transferred across the border. This aspect of the novel circles around questions of what goes with the lung. Some interesting 
work has been done on this by the academic Fay Bound Alberti, who has written about the metaphorical and psychological implications of various parts of the body. ${ }^{2}$ Particularly she has done interesting work with the heart, talking to medical students, who are supposed to be hardened to this kind of thing, about what it is like to handle a heart. They feel there is something different about handling a heart-that if there is a soul the soul might reside there. There is something like that for me in the breath organ, the lung, because voice is so much a part of what identifies people. The idea is that breath is the root of voice, and therefore if you carry the vessel of someone's breath in some sense you are carrying them. That all came into the novel.

The section I want to begin from (Breath, 31-33) concerns the protagonist of the novel, Andrews, a hospital manager in the south of this post-war-torn country. He is suddenly faced with the worst nightmare: his teenage son has been knocked off his bike and killed, and he is asked whether he is willing to allow his son's lung to be donated for a transplant. He is grief-stricken, but he is trying to be a manager as well as a father. Andrews is supposed to be an exemplary figure in healing the post-conflict divide among his staff. He has just been fine-tuning a document about this for other hospitals to use. At the same time he is about to go in to see his dead son, and it is starting to dawn on him that his son's death may be something to do with this sectarian divide. This section exploits the clash of languages David mentionedhumanely emotional from the narrator, coloured by expressions (words, turns of phrase) in which Andrews might actually think and feel; coolly bureaucratic (marked out by a different typeface) for the document he is writing. (As will become evident when I discuss a later passage [pp. 184-86], these different languages are eventually associated with different cultures of air and breathing.)

I'd also like to discuss a section about a prayer (Breath, 26-27). The novel takes place over a single night and flips between three settings. One is Andrews trying to come to terms with the loss of his son, and at the same time struggling with his own demons as a recovering alcoholic among other things. Another is the recipient of the lung, Baras, waiting in a hospital north of the border. He is obsessively talking to a young woman who is the hospital chaplain. He wants something from her: that dialogue becomes a key part of the novel. The third element is the lung in conversation with a pilot who is flying it across the border. The lung has a voice, though you are never sure whether or not it is just in the pilot's head. This is part of the section in which the old man north of the border, Baras, is waiting for the lung to arrive. 
$D F$ : I asked Michael to consider this passage because I was interested in the issue of a prayer memorised in childhood as like 'an implant sewn into the fabric of breath', integrated into the body by the breathing in and out. As the passage shows, Baras has had a religious education, has consciously rejected that education, but in a number of ways continues to have a religious sensibility and religious yearnings. This ultimately expresses itself in a desire for forgiveness, which is understood in religious terms as about penitence and absolution. So though Baras is consciously an atheist, his training means that his body-some preconscious level related to just continuing to breathe-retains elements of religious consciousness in a secular context.

MSR: The Jesus prayer that he recites, as you probably know, is used mainly in Orthodox traditions but has become well known in the West as well. If you look at Russian Orthodox and Greek Orthodox theology some of the main proponents of this practice of prayer felt that it became so mapped onto their breath that just being alive, just breathing, was a constant act of prayer. This intrigued me-and alarmed me.

The last section I want to draw attention to is quite different (Breath, 184-86). This is near the end of the novel. The leading lung transplant surgeon in the country has flown up north, across the border, to carry out Baras's operation. Baras is concerned about what this surgeon from the south is going to do to him. Everything up to this point has been exemplary. The surgeon, Ross, has his team put Baras under anaesthetic, but not fully: he is put under to a point where he can hear but cannot act. This is during that conversation. Ross is telling Baras, who cannot respond or answer back, that he knows what he has done in the war, 'And now one of my people has offered up his lung to give you breath'. His hatred of Baras is expressed in forcing him to consider his own wickedness in using poison gas with an account of the most famous form of death inflicted by extended asphyxiation: 'Do you know what crucifixion is? Do you know what kills you? Do you think they bled to death? No. It's breathlessness. ... Pray for breath, Mr Baras. Pray now for the breath that you denied so many others'.

$D F$ : Before we leave the novel, I should say it has some surprising turns in the end: the apparently southern lung turns out to be more ethnically diverse than it had appeared, and the death of Andrews' son, Jamie, is seen in a different way by the end of the novel-more directly a result of the civil war conflicts: he dies as a result of making overt through his flute-playing - a musical formalisation of the character and expressivity of breath - the northern allegiance drawn from his mixed heritage. I wonder if you could say more, Michael, about the issue of southern and northern lungs needing to breathe different air. This is a brief element 
of the novel, but I think a crucial one in bringing together the civil war and the medical aspects.

MSR: This has to do essentially with the difference in air between the north and the south, and how the lungs of each group differently access the air. I was trying not to map air and breathing too closely, because you are hearing about these from the perspective of one side or the other. I wanted it to be possible that everything you hear from either side about the other could be understood as propaganda. There's a sense in the novel that the north is geographically different (mountainous), that the north has a stronger poetic and musical tradition, and that breath is at the root of that. A flute from the north plays a key role in the novel, as an incendiary symbol of sectarianism but also as a form of liberation and expression. So there is something about northern breath being able to take shapes associated with art, and southern breath being more associated with the sort of bureaucratic language that Andrews finds himself able to compose for his job. I can mention just a couple of anecdotal things that have come to me recently. One is that my eldest son has moved down to London, and when he comes back to Manchester the first thing he does when he gets off the train is to take a huge breath of northern air. This is partly, I suppose, about the perceived pollution in London, but it is more than that: it is about Mancunian air meaning being home. Also I recently had a conversation with a voice coach who works with actors, partly because I thought I might be interested in doing some voice work. Like a lot of poets, I am constantly going around using my voice, and I am not sure I use it well. This voice coach comes from Liverpool. One of the first things he said to me was, 'You are from the north west. My relatives are the same. You have that slightly nasal, slightly sinus-y tone because the air is so damp'. Hence the way the breath functions; hence the way the voice functions. That's why the north west has the history it does: because the air is damp you can work with cotton. That's the story of Manchester-the damp air. So there are two anecdotal reflections on geography, culture, air, breathing, and voice.

In connection with this I'd like to discuss the poem 'The Frequency' from Corpus, which is a book of poems about or related to the body. 'The Frequency' was written when I was working at the BBC as a radio producer. I was interested in the relationship between voice and breath. At that point as a radio producer you spend hours editing on quarter-inch tape - a lost craft now. Breaths were a key part of editing on quarter-inch tape. Before you edited an interview you would run it through and if there were useful breaths that didn't have a hard syllable on either side of them you would cut them out and stick them with 
splicing tape to the side of the machine so that in future edits, where you were trying to get a blade in really fast, you could put a breath in. So you would keep your long breaths in one place and your short breaths in another. This idea of breaths being part of your kit when you were editing an interview was entirely everyday. The other thing you did when working with quarter-inch tape was move the spools to find the exact point to get the blade in when someone was speaking quickly. You would slow the tape down, and when you slow it right down a breath becomes a sound. If it's slow enough on the spooling a breath becomes a vowel sound. This poem is in that area-looking at the point where breath becomes speech. You also realise that words sound like other words when you change the frequency, and that the whole tenor and emotional content of the words changes when you change the frequency as well, so the frequency is not just about speed or pitch. There's more at stake than that.

$D F$ : The poem is about hearing the uncensored language of the heart, hearing something that is normally inaudible. You've said elsewhere that something you go back to often is a sense of wanting or working towards an epiphany. This seems to me a poem you could describe like that, because it's about getting to something that is almost present but you can't normally hear, and that something is located in the breathing. Can you say more about that?

MSR: I think it's one of a number of poems in which I'm looking for connections and continuities between breath and voice, and where breath sits in relation to voice-the idea that the breath might be not just at the root of voice physically, but also that breath might be in some sense a pre-conscious form of voice. The other poem that gets into this territory is 'The Lung Wash', which is about getting behind the voice into breath and through into some essence or epiphany, some revelation. 'The Frequency' does that slightly differently. I was interested in looking at this idea that there could be frequencies we don't know about, frequencies we don't understand. I was asking, if you slow recorded sound almost to a standstill, what comes through? What's behind the voice? That's where breath comes in. But like all these poems, you can say certain things about them, but they are exploratory. I don't have a clear sense of what it is I'm trying to say about the relationship between breath and voice before I start the poem, and the process of writing the poem is part of how you find out and explore what you think about your voice and breath.

$D F$ : So you're hearing vocal sounds which begin as words, but getting to a level where you've divorced them from the words but are hearing an 
expressive articulation which is pre-verbal: it's got a meaning, but not a meaning in the usual way that verbal articulations have.

MSR: Yes. It is that sense of some other level of meaning, some deeper level of meaning that is pre-verbal. Also I'm interested in those ideas of life being effectively bookended by one huge breath, certainly in literary understandings of life. I don't know whether these stand up medically, but I've often thought that the popular conception of the first and last acts of many lives is that you begin with a sharp intake of breath, which I've seen in my own children, and then the crying: the inhaling is the first act, and then the exhaling, famously throughout literature, is the last act, so the whole thing takes place bookended by these acts of breath, and that, if these are the bookends of life, there's something profound and perhaps related to a sense of whatever might continue after or pre-date your life-the ideas of continuity of self, of soul if you like, and that the breath is intricately connected with that.

DF: I want to offer you something of Basil Bunting's, which I am reminded of by this, about the importance of sound to meaning in poetry.

Poetry, like music, is to be heard. It deals in sound-long sounds and short sounds, heavy beats and light beats, the tone relations of vowels, the relations of consonants to one another which are like instrumental colour in music. Poetry lies dead on the page, until some voice brings it to life, just as music, on the stave, is no more than instructions to the player. A skilled musician can imagine the sound, more or less, and a skilled reader can try to hear, mentally, what his eyes see in print; but nothing will satisfy either of them till his ears hear it as real sound in the air. Poetry must be read aloud. ${ }^{3}$

DF: While I fully accept what Bunting says here about reading poetry aloud in a general way, I don't want to believe what he says specifically about vowels and consonants because that seems to involve the sounds of poetry with the accent of the poet. That's an interesting idea, but I don't want to believe it, because if you think that's true then something of all poetry before Tennyson is lost, because we can't imagine at the level of vowels and consonants quite what sounds the poet was hearing. But I'm now tempted to think that this may have some truth in it - that everything about a voice is present in a reading, that is, the whole vocal mechanism, not just the vocal cords but everything that supports them, the whole breathing apparatus. Not perhaps in ways you can understand, but I think how much I like T. S. Eliot's readings, partly because 
I love the sound of his voice, which seems to me to have a characteristic expressivity suited to the poetry.

MSR: I'm wary when an attempt is made to develop a programmatic stepby-step understanding of how to read the sounds of poetry, almost like a musical notation: the consonants do this, the vowels do that. It seems to me that limits the range of responses, and the range of relationships, not just the responses to poetry, but the range of relationships between the reader and the poet's voice in the poem, which differs from poet to poet. I think there is a relationship between the poet's accent, the pitch of their voice, the way they stress things, the complexity of their voice, and the way their poems are made. That seems to me self-evident. But I don't think that means you can't read Bunting unless you can hear the Northumberland accent Bunting had in mind as he was writing. I think that is needlessly precious, and to me uninteresting. The great poets of the past don't depend on being able to recreate a sense of how (say) Shakespeare might have spoken. That seems to me an academic interest not important to the reading of the poem.

DF: I extracted from Michael's jointly written book with Paul Farley, Deaths of the Poets (2017), an anecdote about Byron's larynx and his lungs, which are buried separately where he died at Missolonghi, and asked Michael if he would talk about that and another phrase from the book, 'poetry alive in the heart and on the tongue'-where the heart, the lungs, the larynx, the tongue, and the body as a whole fitted into his sense of where the poem comes from and how the performance of a poem works.

William Carlos Williams talks about the difficulty, but also the necessity, of getting a poem off the page. He argues that you understand a poem by getting it into your voice and constructing the poem as a soundscape for yourself. But a poem can be difficult to get off the page because the printed indicators about what it is meant to sound like as an aural structure are not always straightforward to interpret. Can you talk about those indicators and how the reader realises their implications?the structure of the line; the structure of syntax, and how it interacts with the line; the structure of the stanza; also structures of intonation and other forms of aural inflection, some of which are the corporate possession of all the people who speak the language, some of which can be individual to particular speakers. How do you look at the printed poem and realise that as an aural structure, whether in your actual voice (lungs, larynx, patterns of breathing and intonation) or in the mind's ear?

MSR: William Carlos Williams' views and the anecdote about Byron's larynx and lungs coalesce around the issue of the poet's voice and how 
that works on the page, if it works on the page. Williams is interesting in relation to this. I worked for radio on his poem Paterson, a huge Modernist collage, which I've always very much admired. I think it's a flawed work, but also a brilliant one. We worked with fine actors who understood how to read poetry, and they struggled with parts of it. There are a number of reasons for this. One is that Williams is interested in the page as a visual field, and is therefore not necessarily interested in giving the reader a set of instructions about how to sound the poetry in your own inner voice. Also he is desperately keen to create an American poetic that is not English-bordering on anti-English. He wanted to kick against that tradition-break up and fragment what might sound like a traditional lyrical English voice in a poem. I also think on a broader level the idea of the poet's voice is a complicated and troubled one. There's an assumption that it's something innate, a post-Romantic assumption that there is something almost soul-like about the voicegoing back to what I said earlier about the almost mythic properties of the voice and the breath. Actually I think most poets would say that the 'voice' of their poems - if there is a single voice, and many poets would say there are multiple voices-but if there is a recognisable single voice it's something that, if not wilfully constructed, has arisen out of everything that you've read, a negotiation with what you can and cannot achieve on the page, how interested you are in various formal structures, and so on. It also changes as you write. I certainly would not say to my students that what you have to do is find your voice, because I don't think they or I would know where to look for it. A lot of poets, when they do have a sense that people will know what a poem of theirs sounds like, resist and challenge that as well. So there are complexities around the voice, and in order to talk about poets' voice or voices you have to get beyond that myth of the authentic voice, especially because it shades into ideas of innate genius, deep-rooted inspiration that just comes through this channel of 'voice', and there is still a lot of misleading stuff assumed and written about that-the assumption, for example, that that is how Blake worked, that it all just came and he wrote it down, rather than being something intricate and crafted.

Then there is the issue about William Carlos Williams reading his own poems, and reading them with punctuation that he doesn't give the reader on the page. There are quite a few poets like that-where you know a poem, and admire it, and you hear the poet read it and think, 'they're reading it wrongly'. There was a debate a few years ago about one of the poetry prizes, when actors performed poems at the prize-giving ceremony rather than the poets reading their own work. Some-probably the majority-said that was wrong: poets know how 
to read poems; we don't like actorish reading of poems, etc. Then there was a minority, to which I am more sympathetic, who say that if poets are the only people who can read their poems aloud, that is not a good thing. You still read an Elizabeth Bishop poem or an Auden poem and it works - so it's about the quality of how the actors do it, rather than poets being the only possible deliverers of their poems. Just as there are actors who don't read poems well, so there are poets who don't read poems well. I think there's something again about the Romantic idea of the authenticity and power of the poet's voice that carries through into the idea that they are the only ones who can perform their poems with authenticity in a public space. Something in me wants to resist that.

$D F$ : In a note to his recording of Four Quartets T. S. Eliot says that a poem of any breadth is bound to be able to be read in different ways, and he compares the issue of the composer's performance of a score, saying it's interesting to know what the composer was hearing, but there must be many other ways of performing that score, otherwise the work is too limited. That's somewhat the issue about actors and poets reading, isn't it? A poem should be able to work in different voices, and in different ways. But on what you say about actors and poets my prejudices are on the other side. Of course they are mixed: there are actors I love hearing read poetry-Richard Burton, for example. His voice is so characterful that I have the impression of hearing the whole embodied being in the sound; and I also think his Welsh background means that he doesn't mind half-singing something: that doesn't come across as affected. He can move easily between colloquial tones and quite stylised delivery. However, there's an essay by F. R. Leavis about reading poetry aloud in which he deplores actors reading poems: what he's thinking about is any assumption of an 'actorly' mode which infuses the poem with generalised feeling as a substitute for thinking what the words mean. ${ }^{4}$ So there are two sets of judgements. With hearing poets read their own poems, I think Eliot is interesting in saying the reason for making recordings is that the listener can hear what the rhythms of the poem, the shapes of the poem that can't be notated in print, were to the poet— precisely what shapes the poet was aiming for. ${ }^{5}$

MSR: Probably the prevailing view is the Leavisite opinion that the authentic reading is by the poet themselves. I resist it, and think it's full of assumptions that don't hold. I don't think actors do necessarily read in an 'actorly' way. I don't think there's a single actor's mode of reading. There's a cliché that actors always ham it up, or go for easy emotion. In my experience good actors don't do that. I've had lots of poems read by actors in broadcasts and performances, and the ways of reading have differed, but not because they're actors doing an actorly 
thing. I also question the idea of there being a particular relationship to do with authenticity between the poet's reading voice and the poem. As I think anyone who's been to lots of poetry readings would acknowledge, some poets are terrible readers in terms of appearing to mangle their own poems, appearing not to know how to read their own poems, killing off any light of interest that the audience might have in the poems. So the hallowing of the voice of the poet as being the only way of hearing the power of the poem seems to me fraught with problems and difficulties. Usually a well-made poem-the poems you return to again and again - is susceptible to many different readings. I have often thought about the Poetry Archive opening up recordings of poets we may not have heard reading before. For example, I'd never heard Robert Graves until I heard his recordings on the Poetry Archive website. First a caveat: I am always interested to hear a poet. If a poet I admire is reading I want to go and hear them, but it's not necessarily because I need to get the authentic, or even the best performance of the poems. It's just that I'm interested to see what they do with them. With Graves you realise that these delicate, troubling, but beautiful and absolutely serious lyrics sound parodic, like Harry Enfield doing Mr Cholmondley Warner in the 1950s. It's not just a patrician public school accent. It's an accent with vowel sounds that are no longer used except in Ealing comedies: they're historically an anomaly. So when you get down to the level of the sounds behind the poem, to hear Robert Graves reading his poems is actively setting off a whole range of resonances to do with class, and with a particular period, that damage and undersell the poems now. Though it's interesting to hear him read, if students are interested in Graves, I wouldn't say, apart from just out of interest, listen to him. So I think it's complicated, and I resist the idea that the poet is the only true voice to carry the poem, or that poets are necessarily the best readers of their own work.

$D F$ : On the issue of poets as offering particular ways of reading, Wallace Stevens is a reader I love, and the thing about Stevens that's to me a revelation-which isn't just about Stevens-is how very slowly he reads. The way I think Stevens seems so excellent is that you feel the meanings of the words are passing fully through his mind as he says them. At that pace it allows you really to think and feel the meanings, and to take pleasure in the language as a structure of sounds. The example of Stevens has persuaded me to read a lot of poetry more slowly.

MSR: I think that's why it's interesting, and that is one of the reasons I seek out poets' recordings of their own work. It's interesting to find out how they felt the pace and pitch of their poems should be set. For example, I love hearing Elizabeth Bishop read her poems, though by 
contemporary standards - certainly compared with Stevens-there was a lot less performative delivery and potency in her readings, but nonetheless there's something delicate and very striking about them. So I always find it interesting.

$D F$ : I wonder if we could say more about another of your poems on the breath, 'The Lung Wash'. It took me a while to like this, because the experience the poem describes is so hideous that I found it difficult to read about.

MSR: The poem came from my family history. This is not something that happened to my asthmatic grandfather, nor to me when I had childhood pneumonia, but that is at the back of it. In early adulthood I encountered someone whose father was a chronic asthmatic, and we got talking about it because it's in my family as well. This person's father had gone to Venice to be treated by an Italian doctor who washed lungs, and he was apparently transformed by this treatment, although it's horrifying and barbaric, and sounds like drowning. I think it's a rather unorthodox treatment, and it was told to me anecdotally. ${ }^{6}$ The idea of it then connected with those childhood things, and the sense that there's something about the washing out of the lungs which related to the way my family talked about my grandfather's surgery: that the lungs were bad, that he had asthma and emphysema. So the lungs contained things that shouldn't be there, and in some sense you did want to wash them. It related to all those childhood feelings wondering can't someone clean him out so that he can breathe again. So there was a quite visceral response to this anecdote about the doctor who washes lungs. Then in the process of exploring this in the poem I started to see (because I gathered the treatment took place over a week) that each stage of the washing got you back further and further into earlier more original, more authentic - to you-properties of voice, back behind surface levels of voice into deeper more self-revelatory elements of voice, and then right back to primal sounds, that ultimately turned to breath and potentially to silence. So there I was experimenting with how this treatment could become progressive over the week, and what that would do to voice and breath, and what that might reveal about the person. This is from my second book, Raising Sparks. I was already then-which I carried on being throughout all the work-preoccupied by the idea that I was interested in even as an atheist when I was first writing poems, interested in and even obsessed by, these ultimate issues of transcendence and meaning, and the possibilities of the spiritual. But I could only understand them through the body. I've never understood the category of the spiritual as being unphysical or the antithesis of physicality. 
And so this becomes a sort of metaphysical poem, or a would-be metaphysical poem, partly in that it's an extended conceit, but also because it's trying to reach beyond the physical, but the only way it can go is through being more physical than ever. Your response of finding it difficult to read and unpleasant is part of what it's setting out to donot trying to float out of and above the corporeal, but trying to find whatever transcendence might be by going deeper and deeper into that. $D F$ : I read it now as a poem about everybody's situation of losing touch with meaning by using words too much. I started to read it like that from the lines 'You sought him out, like countless others / who speak too much and breathe too little', and then from where you get to at the end, when the process of cleaning is completed: 'Everything you say is sudden poetry'. There's the idea that it's normal to use words without thinking acutely enough about their meanings, or what it is they're trying to search for, whereas if we could use words more chastely, or more demandingly, voice would come from deeper breathing, language would have a more vivid relation with thought and feeling. Is that too general?

MSR: No, absolutely. That's exactly what those passages are exploring.

$D F$ : I'd like to turn to Mancunia, and a more recent poem about breath, 'The Cold'.

MSR: Mancunia is a book about Manchester but not Manchester. A lot of Mancunians call Manchester Mancunia, as a term of affection for it. I like it because it sounds recognisably Manchester. People from Manchester are Mancunians; my family are Mancunians; so there's history there. Also, it's one of those happy coincidences that during the time I was working on this book, and was thinking about Mancunia as a mythic city as a well as a real city, I was working on Thomas More's Utopia for a dramatisation for Radio 4. So Mancunia in this book becomes a sort of utopia and a dystopia, and it has Thomas More in the background. My premise was that any city has as many versions of itself as there are people living in it. You have your own associations and routes and maps of the city.

'The Cold', takes place in Mancunia. I was interested at the time of writing this in a poem that begins with something concrete and expands, and widens and widens. It's a shape in a poem that I've explored before, and that's what happens here. It begins with a mundane moment: it's snowing and the dog wants to be let out. There's what you could call a snowy, icy, blank whiteness, a version of the dark night of the soul here. There's an emptiness, the idea of an absent God, and the paradox that as soon as you talk about the absence of God you're making God present, and therefore the presence within the absence, one of the great 
paradoxes of mystical writing. I'm interested in that, and in the idea that in this apparent absence the actual presence is as close as the breath on your cheek. I wanted some expression of absolute intimacy, and breath seemed to be that-more so than the voice of God; but the breath of God, with all its biblical resonance as well. I wanted a sense of that paradox: at this moment of bleakness and coldness and emptiness, and the inability to pray, and the lack of confidence that any answer would come even if you did, there's also that absolute intimacy of breath, something so unforced that almost came back to 'The Frequency'. If you're not open to it, if you're not on the right frequency, then it feels like absence. The poem ends in a prayer that arises out of not being able to pray. So the coldness itself becomes a way of riffing into a sort of intercessory prayer for people who are only linked by the connections between them and the cold, especially at the end of their lives. It becomes a prayer for those who are caught in the cold. The image of the breath comes back in the mention of Louis MacNeice, who caught his death of cold with pneumonia in a cave recording the sound of the cave. That also was intriguing to me because what he's recording is pretty much silence, but it's a particular kind of silence in a particular place. So the whole poem is an attempt to explore emptiness, the whiteout of a blizzard, and the silence.

$D F$ : Returning finally to the issue of reading aloud, I'm interested in the physical relation people have to a poem if they get it into their own voice. I've tried teaching about this-helping people to find their own way into the words by getting them into their own vocal mechanism, so that the meanings, forms, and inflections take on the sounds natural to their vocal tones and intonations; so that they can say them in a way that gets them into their own body, their own vocal being. It's with that that I want to go back to that issue of 'poetry alive in the heart and on the tongue'. My sense is that poetry becomes alive in the heart by a sort of mind-body interchange, partly by becoming alive 'on the tongue'. When you have made a poem belong in your own voice, and found your own way of saying it, you have interiorised it in a personal way by that act of getting it into your voice. Is there anything else to say in that area?

MSR: I think learning by heart is connected here. There are all sorts of things we could say about the phrase 'learning by heart', why we associate it with the heart, and so on. One view, which still has currency in some quarters, is that it's old fashioned. On the other hand there's the Poetry By Heart movement-getting young people to memorise and recite poems again. ${ }^{7}$ The link between memorising and speaking has always been there in poetry. When I was a student looking around 
at what poets and poetry were doing, as I was starting to write myself and trying to take it seriously in my teens, the big course on poetry was taught in Boston by Derek Walcott and Joseph Brodsky. I think Seamus Heaney was involved as well. A major principle of that way of teaching was memorising by heart. I think it was driven largely by Derek Walcott's belief in the importance of that. It can become fetishistic, but I think there is a link between the way you say something and having it committed to memory that is valuable, and is to do with the sorts of metaphors you were using of ownership-taking ownership of a poem in your own voice; not just reading it off the page, having possession of it in your memory as well.

But it's also worth exploring what a poem on the page is. It's not quite a musical score, is it? If it were it would be an imprecise one. Most poets don't use punctuation in such a way that there's only one way of reading the poem. There's a pattern there which can be changed, which can be read in different ways; and that relates to poets reading when they read in a different pattern from the one you'd expect from the page. I loved hearing Les Murray read because it told you something about the man: the way he taught and the way he read were very close to the rhythm of his conversation. There was something almost offhand about his conversation, even when he was talking about profound things, and that came through in the way he read the poems, which were far from offhand but were read in an almost, or seemingly, throwaway fashion. The rub between those two things-the apparent mismatch between the tone and pace at which he read (because he often read very fast) and what seemed to be in the poem on the pagewas to me interesting. But it doesn't mean that everyone has to read a Les Murray poem like that.

Seamus Heaney is perhaps one of the most effective readers of his own poetry. I find it almost impossible to read a Heaney poem without hearing his voice in my head. There's such a strong print of his voice on the poems. To some extent it's the same with Ted Hughes. This is partly a generational thing: they were the poets I grew up with and was listening to as a student. That's perhaps why I love Elizabeth Bishop's idiosyncratic readings as well, because of encountering her at the same time. But I'm wary of making a hallowed object out of the poet's delivery of their own poems, because the best poems can withstand any number of voices getting into them, and remaking them, and finding new patterns within them. That's always happened to plays, and consequently dramatists can be less precious about this. It seems part of the fabric of the play as a made object that is therefore a public object: other people can take ownership of it and interpret it in different ways, 
and there's a confidence underlying that that the play is strong enough to survive, and the impact be enhanced by different performances of it. There's something I resist about poetry not allowing that confidence, allowing that breadth, allowing a poem to be sung by someone if they want to sing it to a tune they've made up, or to be read at twice the pace the poet might read it. Poetry suffers from being seen primarily as a form of self-expression: hence all those metaphors about an outpouring rather than a made thing, where the expression comes through the making. If poetry is an act primarily of self-expressionI suppose we get that partly from misreading of the Romantic poets, but also from the confessional generation-then it's hard to imagine other voices reading a poem, because if it's one person's cry from the heart then you need to imagine how it sounded to them. But for me if poems are fundamentally made objects, even when they're purporting to be a cry from the heart, a made object, like a play, is a constructed thing which contains self-expression but also contains much more, and is susceptible to, and should welcome, a range of interpretations and responses, including other people's voices.

$D F$ : What you began from there about Derek Walcott getting students to memorise poems is separate from that isn't it, because they are getting poems into their own physical being. The responsibility is thrown onto them to make the poem their own. Ted Hughes, of course, has an anthology, By Heart, which is about the same thing-memorising as an act of love. ${ }^{8}$

MSR: My own experience has borne that out as well. I don't have a vast range of poems committed to memory, but with the ones I have, I do feel you know them differently. I've got some Auden poems and some Bishop poems in my head, and some Shakespeare sonnets. You do feel there's something unique about your relationship with them because of that, and that when you speak them it's different from having them on the page in front of you and speaking. That does relate to breath, I think. You don't feel you quite take physical ownership of a poem when you're opening a page and reading it. That is more like a musician sight reading, isn't it? There is something about taking and storing it in the physical body and then being able to issue it out that means it's gone through a different process. It's gone right down into you, and is closer to breath. That is intriguing. A few years ago it seemed educationally disreputable - the idea that you had to learn poems by heart. It was associated with people of my grandparents' generation having to learn huge swathes of what they felt was incredibly dull verse, and hating doing it. But I think it is coming back, and has come back. Obviously the spoken word scene has been doing this for years. It's 
one of the hallmarks of it that you don't have a piece of paper or a book in front of you. But Michael Donaghy was famous for reading without a book too. He had it all by heart. Alice Oswald similarly in her Memorial. There's something about having poems in your memory that has a different property of voice and ownership, and again breaks that connection between the poet's voice and the authenticity of the poem.

$D F$ : I'd like now to invite questions from the audience.

Jane Macnaughton. I'm interested by the notion that voice seems to be such an important element of how breath was realised. One of the things that we are struggling with in the Life of Breath project is the extent to which breath seems absent as an issue for consideration within the cultural record. You were saying that it's there, and you are not aware that it's there. People write about it, but don't reflect on the fact that they're writing about it. There's a metaphor there in the editing of the tape, isn't there, that breath is in the gaps that are cut out? It's interesting how breath needs to be expressed by a gap, by a sensation that touches your skin and walks away again. It can't be expressed by what it is itself. It doesn't have any substance that you can talk about, except in these other kind of ways.

MSR: I agree with all that. I think it's fascinating. In some of the circles I move in there is quite a lot of talking and thinking about breath. I think poets do think about and talk about it. Musicians do. Singers do. But in the wider culture perhaps what you say is true. I'm endlessly grateful that I had this early engagement working in radio, working in voice, because I think it's really affected a lot of my other work. It makes you pay minute attention to the nuances of different voices and the rhythms of them. When you are cutting them and shaping them because you have got a one-hour interview that needs to be twenty minutes, it still has to sound like them. Breaths are not just gaps. That's why you have a line of them on your machine: if you put the wrong breath in, it stands out a mile. You hear that it's wrong. It is as much a positive element of speech, in that sense, when you are editing an audio interview, as the words are. Put in the wrong breath and it's completely unconvincing. I suppose from that you become slightly obsessed with it. On radio you notice bad breath edits going through. I also get obsessed by it on television, to the annoyance of my sons.

$J M$ : I was interested in another part of this, also in relation to the project. It's where Baras is talking about his experience of problematic breath, saying he cannot locate this in his own chest. The problem is with the air outside, and that air can change. We've raised this with some of our colleagues in British Lung Foundation 'Breathe Easy' groups, who we 
support with their problems of breathlessness, and they've had lightbulb moments about this. This sense of feeling no, actually it's not me: it's out there. The problem is that the air is not giving me what I want. I wonder where that idea came from for you.

MSR: It goes right back, I think. It was to do with my grandad, trying to make sense of why sometimes his condition turned critical. I suppose you were somehow trying to think, is the air somehow thinner here? Or thinking of analogies with liquids: the idea that somehow they are too thick-because of the physicality of seeing someone struggle with breathlessness. There was something about what he was getting that was wrong, that somehow because our lungs were more robust we were riding over these variations, but that he was like a finely tuned instrument, responsive to changes in the air. I suppose as a child you are trying to rationalise, why is he suddenly rushed to hospital?

This interview was conducted first as part of a public reading and discussion in Durham in March 2018. The text edited and formalised from that occasion was developed in correspondence. This was supplemented by a second interview conducted privately in Manchester in July 2019, and the whole completed through further correspondence.

\section{Notes}

1. Michael Symmons Roberts, Breath (London: Cape, 2008; New York: Vintage/Random House, 2009).

2. Fay Bound Alberti, Matters of the Heart: History, Medicine, and Emotion (Oxford: Oxford University Press, 2012).

3. 'A Statement', in Descant on Rawthey's Madrigal: Conversations with Basil Bunting, ed. by Jonathan Williams (Lexington, KY: Gnomon, 1968), unpaginated.

4. F. R. Leavis, 'Reading out Poetry', in Valuation in Criticism and Other Essays, ed. by G. Singh (Cambridge: Cambridge University Press, 1986), 253-75.

5. 'A poem ... of any depth and complexity ... should be capable of being read in many ways, and with a variety of emotional emphases. ... The chief value of the author's record is as a guide to the rhythms. Another reader, reciting the poem, need not feel bound to reproduce these rhythms.' T. S. Eliot, sleeve note to his recording of Four Quartets, HMV CLP 1115. 
6. 'Washing of the lung', or whole lung lavage, is still in use as a treatment for certain rare lung conditions such as Pulmonary Alveolar Proteinosis, where there is abnormal build up of surfactant, the protein which normally supports lung inflation. [JM]

7. http://www.poetrybyheart.org.uk/.

8. Ted Hughes, ed., By Heart: 101 Poems to Remember (London: Faber, 1997).

\section{Selected Bibliography}

Roberts, Michael Symmons. 1999. Raising Sparks. London: Cape.

Roberts, Michael Symmons. 2004. Corpus. London: Cape.

Roberts, Michael Symmons. 2008. Breath. London: Cape.

Roberts, Michael Symmons. 2016. Selected Poems. London: Cape.

Roberts, Michael Symmons. 2017. Mancunia. London: Cape.

Roberts, Michael Symmons. 2021. Ransom. London: Cape.

The Poetry Archive [sound recordings], https://poetryarchive.org/poet/ michael-symmons-roberts/.

Open Access This chapter is licensed under the terms of the Creative Commons Attribution 4.0 International License (http://creativecommons.org/licenses/ by $/ 4.0 /)$, which permits use, sharing, adaptation, distribution and reproduction in any medium or format, as long as you give appropriate credit to the original author(s) and the source, provide a link to the Creative Commons license and indicate if changes were made.

The images or other third party material in this chapter are included in the chapter's Creative Commons license, unless indicated otherwise in a credit line to the material. If material is not included in the chapter's Creative Commons license and your intended use is not permitted by statutory regulation or exceeds the permitted use, you will need to obtain permission directly from the copyright holder.

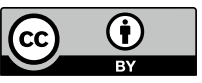

